\title{
Erratum to: A systematic review of quality of life in adults with muscle disease
}

\author{
Christopher D. Graham • Michael R. Rose • \\ Elizabeth A. Grunfeld · Simon D. Kyle • \\ John Weinman
}

Published online: 13 July 2011

(C) Springer-Verlag 2011

\section{Erratum to: J Neurol \\ DOI 10.1007/s00415-011-6062-5}

It has come to the authors' attention that in our systematic review we misquoted one paper (Sansone et al. 2010). Here we stated that quality of life (QoL) was worse in Myotonic Dystrophy (MyoDys) than the other muscle diseases (MDs); Sansone et al. (2010) reported that QoL was in fact better in MyoDys than in the other MDs.

The online version of the original article can be found under doi:10.1007/s00415-011-6062-5.

C. D. Graham $(\bowtie) \cdot$ E. A. Grunfeld · J. Weinman

Department of Psychology, Institute of Psychiatry,

King's College London, 5th Floor Bermondsey Wing,

Guy's Hospital, London SE1 9RT, UK

e-mail: christopher.graham @kcl.ac.uk

M. R. Rose

Department of Neurology, King's College Hospital,

Denmark Hill, London SE5 9RS, UK

S. D. Kyle

University of Glasgow Sleep Centre,

Sackler Institute of Psychobiological Research,

University of Glasgow, 2nd Floor Institute of Neurological

Sciences, Southern General Hospital, Scotland G51 4TF, UK 